\title{
Capacity management, not stock status or economics, drives fleet dynamics in the Bay of Biscay ecosystem on a decadal time scale
}

\author{
Marie-Joëlle Rochet ${ }^{\star}$, Fabienne Daurès, Verena M. Trenkel
}

Institut français de recherche pour l'exploitation de la mer (IFREMER), B.P. 21105, 44311 Nantes CEDEX 03 , France.

*: Corresponding author : Marie-Joëlle Rochet, email address : Marie.Joelle.Rochet@ifremer.fr

\begin{abstract}
:
This paper introduces a semiqualitative approach to analyse the joint dynamics of fleets and stocks in a multispecies, multifleet fishery. We ask whether changes in fleets affect resource dynamics and whether trends in resource influence fleet dynamics more than external drivers do. External drivers include vessel buyback, fuel price, and fish prices, as well as environmental fluctuations. Resource status is measured by abundance and length metrics; fleet capacity is measured by total horse power, and economic metrics such as profitability and earnings are examined as well. A maximum likelihood approach is used to identify the combined metric trends with the largest support in the data. The approach is applied to the French Bay of Biscay fisheries in 2000-2007. Combined-metric time trends suggest that decreases in fleet capacity did not result in decreasing fishing impacts; trends in stocks and fish prices were not the major drivers of changes in fleets either. Rather, the vessel buyback program might have been the main factor determining fleet dynamics over that period.
\end{abstract}

\section{Résumé :}

Notre étude présente une approche semi-qualitative pour analyser la dynamique conjointe des flottilles et des stocks dans une pêcherie multi-spécifique et multi-flottille. Nous examinons si les changements dans les flottilles affectent la dynamique des stocks, et si les tendances des stocks influencent la dynamique des flottilles davantage que des facteurs externes. Ces facteurs incluent un programme de sortie de flotte, les prix du gasoil et du poisson, ainsi que les fluctuations environnementales. L'état des stocks est évalué par des métriques d'abondance et de longueur; la capacité des flottilles est mesurée par la puissance totale; des indicateurs économiques comme la rentabilité et les salaires sont aussi examinés. Les tendances combinées de ces métriques les mieux appuyées par les données sont identifiées par une méthode de maximum de vraisemblance. L'approche est appliquée aux flottilles françaises dans le golfe de Gascogne de 2000 à 2007. Les tendances temporelles combinées suggèrent que la diminution de capacité de la flotte ne s'est pas traduite par une réduction de l'impact de la pêche sur les ressources; les changements dans l'état des stocks et le prix du poisson n'étaient pas non plus les principaux facteurs des changements dans les flottilles. C'est plutôt le programme de sortie de flotte qui semble avoir été le facteur majeur de l'évolution des flottilles pendant cette période. 


\section{Introduction}

The development of an ecosystem approach to fisheries management requires the monitoring and assessment of all dimensions of exploited ecosystems, including ecological, economical and social components (Garcia and Cochrane 2005). In particular, understanding fleet dynamics is essential for effective fisheries management (Branch et al. 2006, Salas and Gaertner 2004). Improved knowledge of fleet-stock interactions at the appropriate, ecosystem scale is necessary to build and parameterize the integrated models required for integrated ecosystem assessment (Levin et al. 2009) and operating models in management strategy evaluation frameworks (Peterman 2004), or to address more general questions such as the ecological impact of rising fuel costs (Sumaila et al. 2008). In a single-stock, single-fleet perspective classical population dynamics models provide appropriate answers. But when it comes to multi-species, multi-fleet fisheries, fleets depend on several fish stocks (Daurès et al. 2009a), and stocks are exploited by several competing fleets (Rijnsdorp et al. 2008). Fleet behaviour changes in response to various factors including technological progress, management regulations, and resource availability (Baelde 2001, Christensen and Raakjær Nielsen 2006). Biological and technical interactions affect stock responses to fishing pressure. Multi-species multi-fleet interactions have been described in various bio-economic models. Some were used to simulate the effects of changes in stock productivity on fleet economic performance (Link and Tol 2006) or to quantify the consequences of fishing mortality, costs and prices on fleet economic performance and stock status (Lane 2008, Ulrich et al. 2002). Some still more complex models describe the complete feedback loop with stock development influencing fleet economy and vice-versa (Hoff and Frost 2008, Pelletier et al. 2009). Unfortunately, given model dimensions, data are hardly available to fully parameterize them and some parameters have to be guesstimated. For the same reason, these models are generally not validated before they are used to simulate the consequences of various management options. Still they are highly sensitive to the input parameter values (Hoff and Frost 2008, Lehuta et al. 2010). Moreover, models rely on a large number of hypotheses about stock dynamics, fleet dynamics, and interactions. It is likely that model results are sensitive to these hypotheses as well, although this has not been directly investigated to our knowledge. This study aims at addressing the need to evaluate basic hypotheses in bioeconomic models by an empirical approach. To do so we attempt to overcome the complications introduced by too many confounding factors by using a semi-qualitative approach.

We ask whether and how fishing pressure impacts fish communities, and whether and how changes in resources affect fleets. Several processes might contribute to the joint fleet-stock dynamics. It has been suggested that to mitigate the risk of fluctuations in the abundance, availability, or price of individual stocks, a diverse portfolio of harvestable resources is an adequate strategy (Hilborn et al. 2001). More broadly, in small-scale fisheries, diversification of target species but also gears, fishing areas, or markets, are used by fishers to manage biological and economic risks (Minnegal and Dwyer 2008). If this hypothesis was true, rapid reactions of fishermen such as changing target species or gear could compensate for changes in resources and complicate the detection of mutual influences. Further, the effects of this portfolio strategy may feed back through resource dynamics, as fishing pressure on a species would be alleviated when this species is depleted, facilitating recovery. Finally, fleet-stock dynamics could be confounded by bottom-up effects of environmental changes and compensation between species (Rochet et al. 2010).

Fluctuations in fleet dependence on a given stock, i.e. the share of each stock in the gross earnings of the fleet (Daurès et al. 2009a), might be a manifestation of changes in species targeting behaviour, and/or of changes in relative stock abundance which could in turn impact 
prices. Conversely, relative species preferences also interact with variable fleet sizes to determine contributions, i.e. the share of fleets in the removals from each stock. Thus contributions and dependences are at the same time the signature of a fleet (Daurès et al. 2009a), and the consequences of short-term adaptations. This dual role might cause quantitative analyses of fleet-stock interactions to be inconclusive because fluctuations in the catch of a given species by a given fleet are the result of fluctuations in i) stock status, ii) fleet preferences, and iii) fleet dynamics (Rochet et al. 2009).

Here, we propose a semi-qualitative analysis of stock and fleet trends as an attempt to avoid circular causations in analyses. The approach is qualitative in two ways. First, we focus on direction, not amount, of change, which implies that we are interested in monotonous, unidirectional, changes. Second, we neglect the relative contributions and dependences, and analyse the influence of fleets on stocks, and of stocks on fleets, on a "yes" or "no" basis. The approach involves a quantitative component in that it relies on a statistical analysis of time series to identify the most likely time trends.

In the Bay of Biscay, species diversity is high (Lorance et al. 2009). Many resources are exploited by a large variety of fleets, and none of the fleets target single species (Daurès et al. 2009a). Over the last decade, important changes have occurred in the regulatory, natural and economic settings of the fleets. The stock of anchovy, one of the major resources in the Bay, has collapsed and the fishery was closed in 2005 with re-opening in 2010 (European Union 2010). Changes have taken place in the fish community that can be partly ascribed to changes in environmental conditions, including water warming (Rochet et al. 2005). Several stocks such as the Northern stock of European hake or the stock of sole in the Bay of Biscay are under rebuilding plans or long-term management plans, which imply sustained reductions in TACs and in fleet capacity (European Union 2004, 2006a). In addition, the long term efforts of the European Union to reduce fishing capacity through repeated Multi-Annual Guidance Plans (MAGP, Guyader et al. 2007) intensified in 2002 under the new Common Fisheries Policy (European Union 2002) under which massive funds were devoted to vessel buyback programmes in many countries (European Union 2006b), including France (Direction des Pêches Maritimes et de l'Aquaculture 2006, Guyader et al. 2007). On the economic side, fuel price has increased sharply since 2005, and ex-vessel fish prices of many species have changed. So the Bay of Biscay provides an appropriate case-study for an integrated assessment of fleet-stock interactions, with a diversity of stocks and fleets and a complex network of interactions in a changing environment.

We analyse the mutual influences between fleets and stocks by asking two questions: did a decrease in fishing pressure cause a detectable decrease in fishing impacts on species? And which drivers among changes in resource status, fleet decommissioning, and changing prices of fuel and fish, had a predominant influence on fleet dynamics? First, we develop a conceptual model to propose fleet-stock interaction hypotheses. We then construct stock-status and fleetstatus metrics and apply them to Bay of Biscay data to assess fleet- or stock-changes over a decade long time scale. In all cases, each fleet fishes multiple species, and each stock is harvested by multiple fleets. To make an overall assessment of status change for combined fleets and stocks, we use a likelihood-based approach. Finally, estimated combinations of fleetor stock- status changes are compared to those predicted by the conceptual model. The approach is applied to the French fleets for which detailed economic data are available. 


\section{Materials and methods}

\subsection{A fleet-stock model}

To propose hypotheses about the mutual relationship between fish stocks and fleets we formulated a conceptual single-fleet single-stock model on an annual time scale (Figure 1). The model is used in a multi-species, multi-fleet context by taking separately the point of view of stocks and fleets. From a stock perspective, the fleet is the combination of the prinicpal fleets that contribute to the catch of that stock. From a fleet perspective, stock is the set of stocks on which that fleet depends. The nodes of the model represent state variables, and the relationships between these variables are not specified by formalized equations but by the signs of interactions, that is, first derivatives near the equilibrium. Resource stock abundance and demographic structure is represented in node $\mathrm{S}$. Fishing capacity $\mathrm{K}$ describes capital invested in vessels and fishing gears. This capacity can be deployed in fishing effort $E$ - the more capacity, the more effort can be deployed. Effort affects stock negatively and both contribute positively to catch $\mathrm{C}$, reflecting the classical catch equation $\mathrm{C}=q \mathrm{ES}$, where $q$ is catchability. Catch generates gross earnings, which are negatively affected by the costs of effort or variable costs, represented by the negative link from $E$ to $R$ (net earnings). Profit is what is left after subtracting remaining costs (non variable and depreciation costs) and crew wages $W$ from net earnings $R$. Profitability $\mathrm{P}$ (profit per capital invested) may motivate reinvestment in fishing capacity; new or existing fishing capacity generates operational non variable costs such as insurance premium or maintenance, represented by the negative link from $K$ to $P$. The model has one positive feedback loop E-C-R-P-K which would tend to destabilise the system when perturbed from the equilibrium; but this positive feedback loop is counteracted by negative links from effort to net earnings (variable costs) and from capacity to profitability (non variable and depreciation costs). This is a model for an unregulated fishery; management actions can be represented as modified links, e.g. subsidies weaken the cost links, or technical management measures modify the link from effort to catch. Other management actions amount to permanent increases or decreases in some variables, e.g. effort by effort control or catch by Total Allowable Catches. Other economic or ecological external drivers might perturb the system. Two economic drivers might affect net earnings, fish prices and fuel price. As it is not easy to determine internal dynamics of fish price in relation to demand and supply, it is often assumed that fish price is exogenous and dictated by the international fish and general food market and economy, which act as external drivers. If fish prices increase for a given level of catch and costs, net earnings will increase. Fuel constitutes a substantial component of fishing costs (Sumaila et al. 2008); e.g. fuel costs amounted to 8 to $22 \%$ of gross earnings in French fleets during the period 2000-2006 (Planchot and Daurès 2008); hence an increase in fuel price is likely to have a noticeable impact on fleet net earnings.

The conceptual model in Figure 1 can be used to make qualitative predictions on the direction of change at equilibrium to be expected from a permanent increase or decrease in model variables. This perturbation analysis can be carried out without specifying the amounts of changes, and the results are qualitative - just the directions of change are predicted (see e.g., Dambacher et al. 2009). We focus on four perturbation scenarios reflecting the major changes in the Bay of Biscay fishery in the early XXIst century: i) variations in environmental productivity, which may result in increased or decreased stock size $S$ ii) vessel buyback programme negatively affecting $\mathrm{K}$ iii) increased fuel price and iv) increased or decreased fish price, both affecting earnings R; we analyse the consequences of these perturbations happening separately or concomitantly. 


\subsection{The Bay of Biscay and data used}

In the Bay of Biscay (Figure 2), temperate-water species occur together with boreal and southern lusitanian species; consequently, species diversity is high. Fish account for 576 species (Lorance et al. 2009), and many species of cephalopods and crustaceans are also present. Many of these resources are exploited by fleets from France, Portugal, Spain, and other EU nations. In coastal areas, demersal and benthic resources are caught using a range of fishing gears, including trawls and dredges, gillnets and trammel nets, lines, traps, etc. In the offshore zone beyond 12 nautical miles (n.mi.) from the coast, trawling is important, but fixed gears are also extensively and increasingly used. This study is restricted to the French fishing fleet. Twenty-seven French fleets fishing primarily in the Bay of Biscay were defined based on fishing gear, location of fishing grounds, and vessel length (Table 1) (Daurès et al. 2009a). Together these fleets land 212 species caught in the Bay of Biscay. The twenty-nine top species which contribute $87 \%$ of this production in value were included in the analysis (Table 2). Note that in several instances, one commercial species corresponds to several biological species.

Vessel technical data (engine power, crew size...) were available for each vessel of the French fleet from the Ifremer Fisheries Information System database (Leblond et al. 2008). Economic data were collected by face-to-face interviews with a detailed questionnaire on vessel costs, earnings, capital invested and employment on board (Daurès et al. 2008). A sample of 250 to 300 vessels is surveyed annually in the Bay of Biscay (Van Iseghem et al. 2011). Among the 27 French Bay of Biscay fleets (Daurès et al. 2009a), the economic survey allows the calculation of time series of economic indicators over the 2000-2007 period for 12 fleets only. Most of them are coastal fleets (1D, 1ES, 1F, 1G, 1H, 1NS, 1P, 1Q, 1S, 1U; see definition of abbreviations in Table 1). Only two fleets of large vessels (2BT and 2NS) are included.

Data on the fish populations were collected during the EValuation des ressources Halieutiques de l'Ouest Europe (EVHOE) survey onboard R/V Thalassa, conducted annually in autumn in the Bay of Biscay (ICES 1991). Fifty to one hundred stations are trawled with a Grande Ouverture Verticale gear according to a stratified random design (Figure 2); the catch is identified to the species and individually measured, which allows us to estimate length- and number-based metrics. Data for the period 1999 - 2009 were used for this study.

\subsection{Metrics}

Fishing pressure but also environmental changes, for instance sea temperature change, may affect stock dynamics and be reflected in stock metrics. The combination of size and abundance population metrics can help to identify causes of changes in stocks (Trenkel et al. 2007). Conversely, stock status also affects fleet dynamics. Both size and abundance of the catch matter to the fishing industry: large fish are often more valuable, and in a context of depleted resources, increases in abundance are generally good news. We described changes in stock $S$ as i) fishing impact on stock and ii) effect of stock on fisheries, based on abundance and size metrics.

The following metrics were calculated for stock $i$ : log-abundance index for the total area $\ln N_{i}$ (total biomass from an acoustic survey was used for anchovy and sardine, ICES 2010), and a large percentile of the population length distribution $L_{0.75, i}$ (average individual weight was used in lieu of length metric for the three Sepia species). The uncertainty caused by sampling variability was also calculated for each metric (Trenkel and Rochet 2003). The two metrics were combined to provide trends in fishing impact resulting from fishing pressure on stocks, and trends in effect 
on fisheries as a consequence of changes in stocks. These changes during the study period were diagnosed with the following combinations of metric time trends:

For the status of stock $i$, increasing fishing impact occurred if $\ln N_{i}$ and $L_{0.75, i}$ decreased; decreasing fishing impact occurred if $\ln N_{i}$ and $L_{0.75, i}$ increased; all other combinations of changes in the two metrics were attributed to "other causes"; when none of the two metrics showed a significant trend, "no change" had occurred in the stock. These combinations of trends are the typical signature of changes in total mortality (Trenkel et al. 2007), which we ascribe to fishing here as the most plausible cause.

For the effect of stock $i$ on dependent fleets, an advantageous stock change took place if $\ln N_{i}$ and/or $L_{0.75, i}$ increased; a disadvantageous stock change took place if $\ln N_{i}$ and/or $L_{0.75, i}$ decreased; all other combinations of changes in the two metrics were termed "other change"; when none of the metrics showed a significant trend, "no change" had occurred in the stock exploited by a given fleet.

\subsubsection{Fleets}

Vessel engine power (measured in $\mathrm{kW}$ ) was used as fleet capacity metric. Capacity data are census data and their sum is easily calculated for each Bay of Biscay fleet (a vessel does not change fleet within a year). As for economic metrics, running or variable costs (depending on effort) are deducted from gross earnings (Landings $\times$ Prices) to obtain net earnings. Crew wages and other costs, considered as "non variable" operational costs are then deducted from the net earnings to obtain the gross cash flow. Finally, the full equity profit is obtained after the deduction of economic depreciation. This full equity profit is divided by the amount of capital invested, of which a good proxy is the insurance value of the vessel to obtain the return on capital or profitability (Le Floc'h et al. 2008a, Whitmarsh et al. 2000). Considering the short time series (2000-2007), all data are nominal data not corrected for inflation. Details on wage and profitability calculations can be found in Daurès et al. (2009b).

\subsubsection{Fleet dependences and contributions}

The economic dependence of fleet $j$ on stock $i$ was defined as $D_{i, j}=Q_{i, j} / \sum_{i} Q_{i, j}$ where $Q_{i, j}$ are the total fleet gross earnings (Euros) from selling stock $i$. The summation in the denominator is with respect to all landed stocks. Conversely, the contribution of fleet $j$ to the exploitation of stock $i$ is the proportion of landings of stock $i$ due to fleet $j C_{i, j}=L, j / \sum_{j} L_{i, j}$ where $L_{i, j}$ are the landings (kg) of stock $i$ by fleet $j$ in a given year (Daurès et al. 2009a).

We identified the principal stocks caught by each fleet as the species that make up $75 \%$ of total annual catch in value of this fleet; the list was calculated annually and any stock that occurred at least in one year was included in the final list (Table 1). Similarly, the principal fleets catching each stock are the fleets that contribute $75 \%$ of total annual catch of this stock; any fleet that occurred in at least one year was included in the final list (Table 2). When several biological species made up one commercial species, each was treated as a separate species caught by the same list of principal fleets.

It might be a strong assumption to treat all stocks identified as the principal stocks of a fleet as contributing equally to its status; and conversely, all fleets identified as principal contributors to the catch of a stock as exerting an equivalent pressure on this stock. To examine the sensitivity 
of results to this "equivalence" hypothesis, all analyses of the links between fleets and stocks were performed in three ways: i) with all principal fleets/stocks bearing an equal weight, meaning that all fleets exert an equivalent pressure on resources and all stocks contribute equally to fleet status; ii) with fleets (stocks) weighted by the inverse rank of their contribution (dependence) to a given stock; and iii) with only one - the most important - fleet or stock.

\subsection{Investigation of model structure}

We investigated the strength of the direct links in Figure 1 by linear regression analysis. For each stock $i$, we examined whether catch depended on biomass $\left(C=\beta_{l}+\alpha_{i} B_{i}+\varepsilon\right.$ where $B_{i}$ is a biomass index from the survey, $\beta_{t}$ and $\alpha_{i}$ are regression coefficients and $\varepsilon$ residuals). For each fleet $j$, we examined whether catch depended on fishing capacity $\left(C=\beta_{j}+\alpha_{j} C_{j}+\varepsilon\right)$, wages or profitability on net earnings $\left(W=\beta_{j}+\alpha_{j} R_{j}+\varepsilon, P=\beta_{j}+\alpha_{j} R_{j}+\varepsilon\right)$, and capacity on profitability $\left(K=\beta_{j}+\alpha_{j} P_{j}+\varepsilon\right)$. In all cases we fitted both a model with a common slope and separate intercepts (e.g., $K=\beta_{j}+\alpha P_{j}+\varepsilon$ ), and a full model with separate slopes and intercepts for each stock or fleet (equations shown above).

\subsection{Identifying joint stock-fleet dynamics}

To make an overall assessment of status change for combined fleets and stocks, we used the sets of qualitative predictions for the directions of change in model variables provided by the perturbation analysis. Time trends in metrics for driving variables were analysed to identify which perturbation scenario seemed to have occurred in the Bay of Biscay. Driving variables were fuel price, fish prices, fishing capacities and stock status. For metrics representing reacting variables the most likely time trend combinations were then identified, each representing the expected impact of a perturbation scenario. Reacting variables were stock status, fleet capacity, net earnings, profitability, and wages.

\subsubsection{Likelihood of time trend scenarios}

All metric time trends were analysed individually using a likelihood approach with two steps (see description in Trenkel and Rochet 2010). The first step consists of fitting three monotonic (increasing, decreasing and stable) time trends by generalized additive models to each standardised metric (i.e., normalized by subtracting mean and dividing by standard deviation; see example in Figure 3). The models are constrained to vary monotonically by an amount significantly greater than the uncertainty in individual data points. For metrics known exhaustively (e.g. fleet capacity or fish price), residual uncertainty was modelled as a $1 \%$ coefficient of variation to account for misreporting or other errors in data collection and aggregation. The second step consists in calculating the likelihood value for each time trend direction.

Capacity changes acting as drivers on each stock were summarised across fleets. For this the overall likelihood of changes in fishing capacity of the principal fleets was calculated for each stock by summing the likelihoods across fleets. For example, the likelihood that the fishing capacity targeting anchovy increased is the sum of the likelihoods that the overall vessel power of each of the four principal fleets which catch this stock (shelf pelagic trawlers, coastal/shelf pelagic trawlers, coastal seiners and shelf mixed bottom pelagic trawlers) increased.

Stock changes representing the impact of driver changes were obtained by multiplying the appropriate likelihoods for $\ln N_{i}$ and $L_{0.75, i}$. For example, the joint likelihood of an increasing 
impact of fishing corresponds to the product of the likelihood for a monotonic decrease in $\ln N_{i}$, and the likelihood for monotonic decrease in $L_{0.75, i}$.

Stock changes acting as drivers on each fleet were summarised across the principal stocks by summing their likelihoods. For example, the likelihood that trends in the resources of Coastal Nephrops trawlers were disadvantageous to that fleet is the sum of likelihoods that each of the four stocks primarily caught by that fleet (Nephrops, hake, sole and monkfish) had either or all their abundance and length metrics decreasing.

For driver and impact scenario analyses, the scenario with the largest likelihood value has the highest support by the data. Scenarios whose likelihood differed by a small amount from the maximum likelihood were considered equivalent. The threshold value for equivalent data support was taken to be $\ln (8)$ based on the (see simulation study in Trenkel and Rochet 2010).

\subsubsection{Consistency between pressures and impacts}

The most likely driver change and impact scenarios were obtained using separate likelihood analyses. We subsequently compare the consistency between identified driver changes and observed impacts with respect to the conceptual fleet-stock model. To do so we examine whether impact scenarios i.e. trends combined according to the right hand columns in Table 3 , are consistent with changes in drivers: the first column in Table 3.

For stock changes, the drivers are the combined trends in fishing capacity of the principal fleets catching this species. Thus our expectations for fishing impacts are provided by the perturbation analysis of changes in fishing capacity only (Table 3). As generally several causes were selected as most likely for changes in stocks, we termed "non increasing fishing impact" the diagnostic for all stocks whose most likely causes of changes included decreasing fishing impact, with or without other causes being also likely.

Several drivers can impact fleets: stock status, fish price, and fuel price in addition to a general decrease in fishing capacity caused by vessel buyback. Therefore we combined trends in fuel price, and in fish prices and stock status of the major species of each fleet, to predict the expected trends in capacity and economic fleet performance metrics. We used "non favourable" and „non detrimental" classification of combined trends as in the case of fishing impacts.

All fleets might not be equally sensitive to increased fuel price. Trawlers use more fuel than passive gears during fishing, and the distance to fishing grounds increases fuel expense en route. To test the hypothesis that fuel price might be an important driver of trends in fishing capacity (in addition to vessel buyback assumed to affect all fleets equally), contingency tables of trends (increasing, no change, decreasing) versus range of activity (coastal, coastal/shelf, shelf) or type of gear (trawlers, other gears) were constructed and independence of rows and columns was tested by Fisher's exact test.

Dependence on a wider diversity of resources may increase fleet resiliency to changes from any cause (Hilborn et al. 2001). As a test of the hypothesis that fishing a wider portfolio of opportunities can buffer fleet variability, we compared the number of species that constitute $75 \%$ of total fleet catch across fleets with increasing, decreasing, and non-changing capacity. 


\subsubsection{Selecting the time horizon}

Selecting the time periods to calculate metric time trends is not straightforward; the time period for fleet metrics is determined by the brevity of the available data time series: 2000-2007. Because predictions of the perturbation analysis are about a change at equilibrium, a time lag is expected between a change in drivers and detectable impacts on stocks, as population age structure creates unavoidable inertia. This time lag is mitigated by the fact that many resources in the Bay of Biscay are overexploited and have a narrow age range, thus low inertia. In addition, the EVHOE survey catches primarily young fish, which react faster than old fish; and the survey takes place at the end of the year, which introduces a ,natural" time lag. Conversely, fleets might also have a delayed response to stock changes, because fleet capacity is a relatively long-term investment (called strategy as opposed to tactics in e.g. Christensen and Raakjær Nielsen 2006), so the reactivity in capacity might be lower than in fishing tactics that determine catch. The time-delay issue was examined by performing the consistency analyses for two time horizons i) without a time delay, and ii) with a one- or two-years delay. For impacts on stocks: fleet capacity trends during 2000-2007 affected stock status during the period 2000-2007, 20012008, or 2002-2009; for impacts on fleets: trends in stocks and fish price during 1999-2006 or 2000-2007 affected changes in fleet capacity during 2000-2007.

\section{Results}

\subsection{Model results}

Perturbation analysis of the model in Figure 1 shows that there is little ambiguity in the predicted directions of change (sign) in state variables when single variables are increased permanently (Table 3). For example an increase in stock is predicted to have a positive impact on all other variables; conversely, a decrease in fishing capacity or in fish price or an increase in fuel price are all expected to be beneficial to the stock. In contrast, when several drivers change simultaneously, the outcome is generally uncertain (ambiguous). The observed vessel buyback programmes and increasing fuel price affect all fleets and are expected to be favourable to stocks and to decrease fleet capacity, although the direction of effects on net earnings and profitability are not predictable without parameterising the relative strength of model links (Table 3 ). When changes in other drivers are added, however, the outcome is qualitatively unpredictable. For example, favourable changes in both stock status and fish price might overcome the detrimental effect on fleets of vessel buyback and increasing fuel price only in certain specific conditions. The outcome will depend on the relative magnitude of changes in drivers and the strength of their influence on fleet dynamics, but also on all other links within the model.

\subsection{Strength of direct links}

Regression analysis showed that species catch was not related to stock biomass $(P=0.3)$, suggesting that stock availability is not the main driver of catch. By contrast, catch was strongly, positively related with fleet capacity for all fleets together $\left(P<2.10^{-16}\right)$, and for a majority of fleets taken separately. Catch in turn was positively related to net earnings for one single fleet, coastal seiners $\left(P=3 . e^{-6}\right)$. Net earnings were positively related with wages for all fleets together $\left(P<2.10^{-}\right.$ ${ }^{16}$ ), and for all fleets but one taken separately; but profitability was independent from net earnings $(P=0.4)$, and capacity was independent from profitability $(P=0.99)$. So the strong direct links identified in the data are from capacity to catch (via effort for which no data was available), 
and from net earnings to wages. The other links are weaker so that co-variations are likely to be influenced by indirect effects.

\subsection{Changes in individual metrics}

Several fleets such as coastal non-exclusive trawlers (Figure 3a) had a marked decline in capacity while others showed an increase; in some cases the trend was non monotonous or happened just during part of the time series, for example capacity of coastal/shelf bottom trawlers decreased in 2001-2002 and then increased again in 2003-2004 (Figure 3b). In the latter case the difference in likelihood between "no change" and "decrease" is lower than in the former example. A few fleets showed increasing economic metrics, but the signal was often unclear owing to annual variability and/or high sampling error (Figure 3).

Trends in stock metrics were often unclear owing to high annual variability (Figure 4). Annual fluctuations also made the trend results sensitive to the time period used for analysis. For example, monkfish most likely increased in abundance over 1999-2006 but decreased over 2001-2008 (Figure 4). Many fish prices were more likely to have increased than decreased over 1999-2006, but again analysing 2000-2007 changed the relative likelihood of trend directions, for example for anchovy or sea bass (Figure 4).

Fuel price increased steadily between 2002 and 2008, with sharp jumps in 2005 and 2008 (Figure 5).

\subsection{Principal fleets and principal stocks}

Some stocks such as sardine or anchovy were primarily fished by one or a few fleets, while for other species e.g. sea bass many fleets contributed each a small share of the catch (Figure 6), such that the list of principal fleets for each stock included 2 to 20 fleets (Table 2). The lists of principal fleets were slightly longer than Figure 6 would suggest owing to annual variability; remember that the list of major fleets includes all fleets contributing $75 \%$ of landings in at least one of the years 2000-2007. Conversely, some fleets depended on a small number of stocks, e.g. shelf pelagic trawlers depend on anchovy, sea bass, and tunas, while other fleets had a much more diversified portfolio of species, such as coastal exclusive trawlers (Figure 7). The principal stock lists included 3 to 29 species; for six coastal fleets the 29 stocks accounted for less than $75 \%$ of total production, because they depended on other valuable species caught in small amounts, such as eel or lobster.

\subsection{Impact of fishing on stocks}

The combined trend in fishing capacity of the major fleets catching each stock was generally decreasing, or unclear in the case of anglerfish and monkfish (Figure 8). Only for megrim and cuckoo ray did fishing capacity increase; both are caught by a small number of principal fleets, among which shelf bottom trawlers increased, but this trend is most probably determined by one influential data point at the end of the time-series (not shown). With a one-year time-lag, the impact of this overall decreasing fishing capacity on stock status was generally not detectable, with 14 out of 25 species with data showing no change as the most likely process. A decrease in fishing impact was found likely in five stocks and an increase in fishing impact in three, but this was never the only likely process (Figure 8).

Assuming that fishing capacity was the major driver for stocks, little agreement was found between identified and predicted impact scenarios. Among the 20 stocks for which fishing capacity was decreasing, for only three was ,non increasing fishing impact" among the most likely processes; other causes or no change were most likely in 16 cases, and for one increased 
fishing impact was even likely (Table 4a). The picture was different when the analysis was carried out without a time-lag, that is, examining trends in fishing impact on stocks over 20002007. Over that period just mullets had a likely increase in fishing impact, while 12 species had a non increasing fishing impact (not shown). As a result, the agreement between main pressure and impact was improved, with 12 species out of 25 showing consistent trends in pressure and impact (Table 4b). Still, 10 stocks with decreasing fishing capacity had stationary or increasing fishing impact. The hypothesis of a delay between the decrease in fishing pressure and its impact does not seem to hold here. With a two-year time lag the results are still different, but more similar to the one-year lag than to no time-lag, with five instead of four species showing consistent trends in pressure and impact.

The analysis of sensitivity to the equivalence hypothesis showed that results with fleets weighted by inverse rank of contribution were very similar to those with non weighted units contributing equally to impacts. Therefore only the latter are shown. By contrast, considering only the most important fleet significantly changed the results: more stocks (eight instead of two) were exploited by increasing capacity, but this did not improve the consistency between fishing pressure and impact, on the contrary. This also applies to the effects of stock status on fleets (not shown): simplifying the picture into a one-fleet-one-stock model did not simplify the interpretation.

\subsection{Effects of stock status on fleets}

Trends in stock status and prices of the principal stocks over 1999-2006 were mostly favourable to fleets (Figure 9). One fleet, Shelf netters, had a decreasing trend in its fish prices; this fleet depends on hake, monkfish and albacore tuna, the three of which had decreasing prices over that period (Figure 4). Two fleets had ambiguous trends in their fish prices and one, shelf pelagic trawlers, had no detectable change in its stock status. Although fuel price increased in general (Figure 5), the combination with positive trends in fish prices and resource status was expected to be mostly favourable to fleets (Table 3). However, only four fleets increased in capacity while eight decreased and eleven showed no significant trend (Figure 9, Table 5a). Here again removing the time lag significantly changed the results, with 9 fleets having increasing prices of their major stocks over 2000-2007 and 15 decreasing prices (not shown). Trends in resource status were less sensitive to the change in time-lag with stocks exploited by coastal mixed nets and hooks having ambiguous trends in addition to those of shelf pelagic trawlers. In that case however, adjusting the time-lag did not improve the agreement with expectations, and still a majority of fleets had no consistency between the trends in their external drivers and in their capacity (Table 5b).

Fisher"s tests did not detect any significant links between trends in capacity and either range of fishing activity $(P=0.60)$ or type of gear $(P=0.22)$; as the assumed level of fuel consumption does not affect fleet trends, this suggests that fuel price was not an important driver of the dynamics of these fleets. The number of stocks accounting for $75 \%$ of total catch varied widely within groups of fleets with similar capacity trend; it averaged 15.8 for decreasing, 16.3 for increasing, and 12 for non-changing fleets, providing no support for the portfolio effect hypothesis under which more species should buffer fleets against changes (one way ANOVA P=0.63).

Among the 12 fleets with economic data, all had "favourable" trends in fish prices and stock status. Three had an increase in net earnings; among those, two increased the wages of seamen, and one, coastal liners, had increased profitability. The capacity of coastal liners did not decrease, contrary to the other two with increasing net earnings (Figure 10). Coastal seiners, the only fleet with economic data and an increasing capacity, had no trend in either economic 
variable (Figure 10); the increase in capacity is most probably determined by one single influential data point at the start of the time-series (Figure 3).

\section{Discussion}

Changing multiple drivers in a multi-stock, multi-fleet fishery creates complex dynamics. The semi-qualitative approach taken here suggested that the counteracting effects of these drivers preclude predicting the expected direction of changes in fleets and stocks unless some links are dominant. Hence, we examined trends in data to identify whether some major drivers would dominate the dynamics. We could find some evidence that decreasing fishing pressure measured by fishing capacity resulted in decreasing fishing impacts on stocks, but evidence decreased when the time lag was increased. We could find no evidence that advantageous trends in stock status and/or fish prices were indeed favourable to fleets as few increases in capacity were observed. There was no evidence either that fuel price or a portfolio effect would make a difference among fleets. Moreover, economic performance did not seem to determine trends in fleet capacity. Therefore the major driver of fleet dynamics in the Bay of Biscay 20002007 seems to have been the vessel buyback programme.

All these findings are conditional on a fixed, relatively short time-period dictated by data availability. The qualitative prediction of the impacts of multiple changes assumes all changes in drivers occurred at the same time, at the beginning of the time series. Of course this is not actually the case and some changes might have started several years prior to the analysis, e.g. favourable environmental conditions in the Bay of Biscay, while the increase in fuel price actually happened in the middle of the time series, and the vessel buyback programme intensified in 2006. We still assumed that the impacts of the strongest drivers should be detectable with our approach. With this general caveat in mind, we first discuss the impact of decreasing fishing pressure, then the drivers of fleet dynamics, and the strengths and weaknesses of the semiqualitative approach.

\subsection{Did the decrease in fishing pressure translate into decreasing fishing impact?}

Many stocks had increasing trends in either log-abundance or length-metric, but few showed unambiguously the combined trends that would indicate a decrease in fishing impact, especially over the period 2000-2007. A first explanation might be that decreasing capacity did not translate into decreasing fishing pressure, either because there was latent fishing capacity to start with, or because increasing fishing power would have compensated for decreased capacity (Marchal et al. 2007). However, landings and fishing mortality of most major stocks in the Bay of Biscay have decreased over the last 10 to 20 years (ICES 2008), and we also found that fleet landings and capacity were strongly correlated, thus it seems that the decrease in capacity actually resulted in decreased fishing pressure. Increasing the time-lag between pressure and impact does not improve consistency - on the contrary, waiting one or two more year makes the consistency between pressure and impact worse. We could ascribe the disappointing finding that decreased fishing pressure is not sufficient to decrease fishing impacts on stocks to interference with other factors. This would be consistent with the results of a more detailed analysis of trends in the Biscay fish community during 1995-2006, which suggested that trends in stock and community metrics were equally ascribable to decreasing fishing pressure, increased environmental productivity, or a combination of factors (Rochet et al. 2010). 
Alternatively, if we believe that year-to-year fluctuations are not just noise and sampling error, we could interpret this result as the consequence of multiple impacts propagating through the system. Looking without a time-lag, we see the direct effects of decreased fishing pressure as a decreased fishing impact on 10 out of 20 species. Waiting one or two more years, the indirect consequences of increased fuel price, improving stocks and varying fish prices complicate the picture. The qualitative analysis suggests that the consequences of multiple changes at equilibrium are largely unpredictable. Thus, fishing capacity would be an appropriate metric of fishing pressure and would be a significant driver of stock status, but at the system level its effects would be damped down by interactions with other factors, such as economic and environmental drivers.

\subsection{Which factors drive fleet dynamics?}

Our results support the assumption that the vessel buyback programme has been a major driver of changes in fleet capacity during 2000-2007. Let us examine more closely those four fleets whose capacity increased. Positive trends in both shelf bottom trawlers and coastal seiners were most probably determined by single influential data points, thus the increase in capacity cannot be taken for granted in those two cases. The remaining two cases, shelf mixed bottom pelagic trawlers and coastal netters, both had unambiguously increasing trends in capacity (not shown). Both fleets depend on a wide mix of species (Table 1). The former might have attracted vessels formerly belonging to the pelagic trawlers fleets, which have been declining owing to the closure of the anchovy fishery; those vessels might have reacted by diversifying their targets. As for coastal netters, increasing fuel price may have made it an attractive fleet, as both nearby fishing grounds and the fishing method imply low fuel costs compared to other fleets.

Fleet dynamics do not seem to be driven by stock status on the annual time scale. Fleets have been found to adapt their fishing tactics to local resource availability (Vermard et al. 2008) or to change their fishing strategies in response to decadal changes in stocks (Holley and Marchal 2004). However, there have been few studies at an intermediate time scale (Daurès et al. 2009a). This may be the scale where the portfolio effect would compensate for changes in stocks. Although we accepted the null hypothesis that trends in fleet capacity were not linked to the number of species in the principal species list, this might not be a rejection of the portfolio hypothesis. First, our test was weak and did not control for many confounding factors. Moreover, in this fishery none of the fleets depend on a single resource; there is always a mix of at least three stocks to buffer resource fluctuations. The threshold for the portfolio effect might be just one versus several stocks. This is even true for fleets targeting anchovy - while Shelf mixed bottom pelagic trawlers are the most important contributor to anchovy landings, they depend on 12 species.

The effects of fuel price increase and of the vessel buyback programme on fleet capacity are predicted to be qualitatively the same. Trends in net earnings or profitability would distinguish among both causes if just one would have changed, but as they changed at the same time their consequences are likely to be confounded, and the effect on economic variables is uncertain. However no difference between fleets ascribable to their assumed level of fuel consumption could be detected - contrary to a similar analysis in UK fisheries (Abernethy et al. 2010), we could not reject the null hypothesis that the level of fuel consumption would make a difference in trends in fleet capacity. Compensation between fleets might have been caused by fuel subsidies paid during 2005 and 2006, provided by a fuel insurance partly funded by the government, as well as exemption of various taxes (Le Floc'h et al. 2008b, Mesnil 2008). As a result, in this fishery as in many other places, fuel subsidies might absorb the fuel price increase (Sumaila et al. 2008) and buffer the differences between fleets. 
We found few changes in economic metrics and they were not linked to trends in fleet capacity. This might be ascribed to limitations of our data, the first of which being that the survey to collect economic data for year $y$ takes place at the beginning of year $y+1$, so that the vessels which left the fleet are never sampled. This might introduce a serious bias, as exiting vessels are generally the least efficient ones (Squires 2010). In addition, low sample size leads to uncertainty and non-monotonous fluctuations. This notwithstanding, it would not be surprising that, here again, subsidies and various other public aid mechanisms would have buffered the effects of economic drivers on fleet dynamics. Indeed the French fishing sector has benefited from massive public aid over the last decades (Mesnil 2008).

The quasi-independence between trends in stocks and economic drivers and in capacity, on one hand, and trends in fleet economic variables and capacity on the other hand, suggests that, in the case of the Bay of Biscay in the early XXIst century, the major driver of fleet dynamics has been capacity regulation. Although the fisheries in the Bay of Biscay were found to be largely unregulated over the last decades of the XXth century, with the landings varying independently of TACs (André Forest, Ifremer, B.P. 21105, 44311 Nantes, France, personal communication 2010), the vessel buyback programme seems to have been more effective. Buyback programmes often succeed in reducing fleet capacity when they are implemented (Clark et al. 2005, Squires 2010). This would support the case that in the European context, capacity and effort controls would have a potential to overcome some of the deficiencies of TACs (Cotter 2009). However, one must keep in mind that these programmes can have counter-productive consequences on long term fishermen behaviour (Clark et al. 2005, Squires 2010).

\subsection{Strengths and weaknesses of the semi-qualitative approach}

Trend analyses appeared to be sensitive to the influence of single data points, especially when they are at the start or end of the time series. Linear regression may be as sensitive to end points when the number of data points is small. This sensitivity may be viewed as a strength or a weakness depending on the preference between power or robustness of the analysis. Combining results across a large number of metrics or fleets or species prevents the overall results to be sensitive to single data points. Rather, since a one-year shift in the time period resulted in a massive change in diagnostic on fishing impacts, this suggests that many stock metrics changed dynamics at the same time. This change might be an artefact of environmental conditions during the survey (Poulard and Trenkel 2007); however, as an additional one-year shift conserves the changes, one cannot eliminate the hypothesis of a broader change in the fish community. Sensitivity to single points is obviously high because the time-period for analysis is short (eight years). However, longer time-periods would make it increasingly difficult to justify monotonous trends. With longer time periods the likelihoods of increases and decreases would become more similar, and less changes would be detected in the system. Certainly the analysis could be improved if a longer data time-series were available, but within a relatively low limit. Again this is a matter of preference between power and robustness - and of prior belief on the time scale of processes.

The analysis relies on a number of arbitrary choices, such as the $75 \%$ threshold for the proportion of the catch that determine the lists of principal fleets or principal species, or the selection of time lags. A different weighting of units suggested that this choice did not make a qualitative difference in the outcomes. The more extreme option of matching each stock with its most important fleet (or reverse) indeed made a difference. This clearly shows that this multispecies multi-fleet fishery cannot be simplified into separate one-fleet-one-stock components. Another arbitrary choice is the choice of the threshold for significant log-likelihood difference (In8), which again is related to the balance between power and robustness. A detailed sensitivity 
analysis of all arbitrary options is beyond the scope of this paper, which aims primarily at demonstrating the method.

Focusing on direction of changes, seeking monotonous trends and relying on lists of equivalent fleets or target stocks made our approach qualitative. This simplification helped to determine causes and effects and to organize the links between metrics. We were able to detect gross trends - e.g., that although not all fleets decreased in capacity, the overall trend in fishing pressure was primarily decreasing; conversely, although not all species were improving, the overall trend in resource was mostly favourable. We identified that the main driver of fleet dynamics has been capacity management and that decreasing fishing impacts were confounded with multiple drivers of stock dynamics. However, the sensitivity to the time-period selected for analysis tells us either that all this is just non-interpretable noise, or that the complexity of the system makes it very difficult to detect a simple signal in the data. Interplays among environmental forcing, population dynamics, and fisheries dynamics, are complex even in fisheries with a less diverse pool of resources such as tuna fisheries (Rouyer et al. 2008). Thus results from more complex, quantitative models, even if steered with data, will likely be largely dependent on model assumptions.

\section{Acknowledgements}

This contribution received financial support from the Biodiversity project ANR-IFB 2005 "Global change, dynamics of exploited marine biodiversity, and viability of fisheries (CHALOUPE)", the EU-funded research project FP6 - 044227 "Indicators for fisheries Management in Europe (IMAGE)", and the EU FP7 grant FACTS (Forage Fish Interactions), grant agreement no. 244966. We thank Jeremy Collie and three anonymous referees for useful comments on earlier versions of this manuscript.

\section{References}

Abernethy, K.E., Trebilcock, P., Kebede, B., Allison, E.H., and Dulvy, N.K. 2010. Fuelling the decline in UK fishing communities? ICES J. Mar. Sci. 67(5): 1076-1085.

Baelde, P. 2001. Fishers' description of changes in fishing gear and fishing practices in the Australian South East Trawl Fishery. Mar. Freshwater Res. 52: 411-417.

Branch, T.A., Hilborn, R., Haynie, A.C., Fay, G., Flynn, L., Griffiths, J., Marshall, K.N., Randall, J.K., Scheuerell, J.M., Ward, E.J., and Young, M. 2006. Fleet dynamics and fishermen behavior: lessons for fisheries managers. Can. J. Fish. Aquat. Sci. 63: 1647-1668.

Christensen, A.-S., and Raakjær Nielsen, J. 2006. Fishermen"s tactical and strategic decisions A case study of Danish demersal fisheries. Fish. Res. 81 258-267.

Clark, C.W., Munro, G.R., and Sumaila, U.R. 2005. Subsidies, buybacks, and sustainable fisheries. J. Environ. Econ. Manag. 50: 47-58.

Cotter, J. 2009. Reforming the European Common Fisheries Policy: a case for capacity and effort controls. Fish Fish. 11(2): 210-219.

Dambacher, J.M., Gaughan, D.J., Rochet, M.J., Rossignol, P.A., and Trenkel, V.M. 2009. Qualitative modelling and indicators of exploited ecosystems. Fish Fish. 10: 305-322.

Daurès, F., Rochet, M.J., Van Iseghem, S., and Trenkel, V.M. 2009a. Fishing fleet typology, economic dependence, and species landing profiles of the French fleets in the Bay of Biscay, 2000-2006. Aquat. living resour. 22(4): 535-547. 
Daurès, F., Van Iseghem, S., Demanèche, S., Leblond, E., Brigaudeau, C., Guyader, O., and Berthou, P. 2008. Re-assessing the French small-scale coastal fisheries: from fleet activity to economic performance. ICES CM 2008 / K:10.

Daurès, F., van Iseghem, S., Leblond, E., and Brigaudeau, C. 2009b. Assessing the economic status and the viability of the French fishing fleets in the Bay of Biscay from 2000 to 2007. ICES 2009 / O: 11.

Direction des Pêches Maritimes et de l'Aquaculture. 2006. Note de service DPMA/SDPM/N2006-9604 du 18/05/2006. Available from http://agriculture.gouv.fr/IMG/pdf/dpman20069604z.pdf.

European Union. 2002. Council Regulation (EC) No 2371/2002 of 20 December 2002 on the conservation and sustainable exploitation of fisheries resources under the Common Fisheries Policy. Official Journal of the European Union L 358: 59-80.

European Union. 2004. Council Regulation (EC) No 811/2004 of 21.4.2004 establishing measures for the recovery of the Northern hake stock. Official Journal of the European Union L 150: 1-11.

European Union. 2006a. Council Regulation (EC) No 388/2006 of 23 February 2006 on the sustainable exploitation of the stock of sole in the Bay of Biscay. Official Journal of the European Union L 65: 1-4.

European Union. 2006b. Council Regulation (EC) No 1198/2006 of 27 July 2006 on the European Fisheries Fund. Official Journal of the European Union L 223: 1-44.

European Union. 2010. COUNCIL REGULATION (EU) No 23/2010 of 14 January 2010 fixing for 2010 the fishing opportunities for certain fish stocks and groups of fish stocks, applicable in EU waters and, for EU vessels, in waters where catch limitations are required and amending Regulations (EC) No 1359/2008, (EC) No 754/2009, (EC) No 1226/2009 and (EC) No 1287/2009. Official Journal of the European Union L21: 1-120.

Garcia, S.M., and Cochrane, K.L. 2005. Ecosystem approach to fisheries: a review of implementation guidelines. ICES Jounal of Marine Science 62(3): 311-318.

Guyader, O., Berthou, P., and Daurès, F. 2007. Decommissioning schemes and capacity adjustment: a preliminary analysis of the French experience. In Fisheries buybacks. Edited by R. Curtis and D. Squires. Blackwell Publishing, Oxford. pp. 105-132.

Hilborn, R., Maguire, J.-J., Parma, A.M., and Rosenberg, A.A. 2001. The Precautionary Approach and risk management: can they increase the probability of successes in fishery management? Can. J. Fish. Aquat. Sci. 58: 99-107.

Hoff, A., and Frost, H. 2008. Modelling combined harvest and effort regulations: the case of the Dutch beam trawl fishery for plaice and sole in the North Sea. ICES J. Mar. Sci. 65: 822831.

Holley, J.-F., and Marchal, P. 2004. Fishing strategy development under changing conditions: examples from the French offshore fleet fishing in the North Atlantic. ICES J. Mar. Sci. 61(8): 1410-1431.

ICES. 1991. Report of the study group on the coordination of bottom trawl surveys in sub-areas VI, VII and VIII and division IXa. ICES C.M. 1991 / G: 13.

ICES. 2008. Report of the working group on ecosystem effects of fishing activities (WGECO) May 6-13 2008, Copenhagen, Denmark ICES CM 2008 / ACOM:41, ICES, Copenhagen.

ICES. 2010. Report of the Working Group on Anchovy and Sardine (WGANSA), 24-28 June 2010, Vigo, Spain ICES CM 2010/ACOM:16.

Lane, D. 2008. Fishing in the NAFO regulatory area: integrated modeling of resources, social impacts in Canada and EU fleet viability. J. Northw. Atl. Fish. Sci. 39: 119-145.

Le Floc'h, P., Daurès, F., Brigaudeau, C., and Bihel, J. 2008a. A comparison of economic performance in the fisheries sector: a short and long term perspective. Mar. Policy 32: 421431. 
Le Floc'h, P., Thébaud, O., Boncoeur, J., Daurès, F., and Guyader, O. 2008b. Une évaluation des performances économiques de la pêche côtière : le cas de la Bretagne. Revue d'Economie Régionale et Urbaine 5: 753-771.

Leblond, E., Daurès, F., Berthou, P., and Dintheer, C. 2008. The Fisheries Information System of Ifremer: a multidisciplinary monitoring network and an integrated approach for the assessment of French fisheries, including small-scale fisheries. ICES CM 2008/ K: 11.

Lehuta, S., Mahévas, S., Petitgas, P., and Pelletier, D. 2010. Combining sensitivity and uncertainty analysis to evaluate the impact of management measures with ISIS-Fish: parine protected areas for the Bay of Biscay anchovy (Engraulis encrasicolus) fishery. ICES J. Mar. Sci. 67: 1063-1075.

Levin, P.S., Fogarty, M.J., Murawski, S.A., and Fluharty, D. 2009. Integrated ecosystem assessments: developing the scientific basis for ecosystem-based management of the ocean. PLOS Biology 7(1): 23-28.

Link, P.M., and Tol, R.S.J. 2006. Economic impacts of changes in the populations dynamics of fish on the fisheries of the Barents Sea. ICES J. Mar. Sci. 63: 611-625.

Lorance, P., Bertrand, J.A., Brind"Amour, A., Rochet, M.J., and Trenkel, V.M. 2009. Assessment of impacts from human activities on ecosystem components in the Bay of Biscay in the early 1990s. Aquat. living resour. 22(4): 409-431.

Marchal, P., Andersen, B., Caillart, B., Eigaard, O., Guyader, O., Hovgaard, H., Iriondo, A., Le Fur, F., Sacchi, J., and Santurtún, M. 2007. Impact of technological creep on fishing effort and fishing mortality, for a selection of European fleets. ICES J. Mar. Sci. 64: 192-209.

Mesnil, B. 2008. Public-aided crises in the French fishing sector. Ocean Coast. Manage. 51: 689-700.

Minnegal, M., and Dwyer, P.D. 2008. Managing risk, resisting management: stability and diversity in a Southern Australian fishing fleet. Hum. Org. 67(1): 97-108.

Pelletier, D., Mahévas, S., Drouineau, H., Vermard, Y., Thébaud, O., Guyader, O., and Poussin, B. 2009. Evaluation of the bioeconomic sustainability of multi-species multi-fleet fisheries under a wide range of policy options using ISIS-Fish. Ecol. Mod. 220: 1013-1033.

Peterman, R.M. 2004. Possible solutions to some challenges facing fisheries scientists. ICES J. Mar. Sci. 61: 1331-1343.

Planchot, M., and Daurès, F. 2008. Le secteur français des pêches maritimes face à l'augmentation du prix $\quad \mathrm{du}$ gasoil. http://www.ifremer.fr/sih/affichagePageStatique.do?page=/produits/rapports_syntheses/not es_synthese/note_synthese_GASOIL_SIH-juillet_2008.pdf, Ifremer, Brest.

Poulard, J.-C., and Trenkel, V.M. 2007. Do survey design and wind conditions influence survey indices? Can. J. Fish. Aquat. Sci. 64: 1551-1562.

Rijnsdorp, A.D., Poos, J.J., Quirijns, F.J., HilleRisLambers, R., De Wilde, J.W., and Den Heijer, W.M. 2008. The arms race between fishers. J. Sea Res. 60: 126-138.

Rochet, M.-J., Daurès, F., Van Iseghem, S., and Trenkel, V.M. 2009. The joint dynamics of fish stocks and fishing fleets: testing hypotheses in the Bay of Biscay. In ICES CM 2009/O: 08 p. 17.

Rochet, M.-J., Trenkel, V.M., Bellail, R., Coppin, F., Le Pape, O., Mahé, J.-C., Morin , J., Poulard, J.C., Schlaich, I., Souplet, A., Vérin, Y., and Bertrand, J.A. 2005. Combining indicator trends to assess ongoing changes in exploited fish communities: diagnostic of communities off the coasts of France. ICES J. Mar. Sci. 62(8): 1647-1664.

Rochet, M.J., Trenkel, V.M., Carpentier, A., Coppin, F., Gil de Sola, L., Léauté, J.-P., Mahé, J.C., Maiorano, P., Mannini, A., Murenu, M., Piet, G.J., Politou, C.-Y., Reale, B., Spedicato, M.T., Tserpes, G., and Bertrand, J.A. 2010. Do changes in environmental pressures impact marine communities? An empirical assessment. J. Appl. Ecol. 47(4): 741-750. 
Rouyer, T., Fromentin, J.M., Ménard, F., Cazelles, B., Briand, K., Piannet, R., Planque, B., and Stenseth, N.C. 2008. Complex interplays among population dynamics, environmental forcing, and exploitation in fisheries. Proc. Natl Acad. Sci. USA 105(14): 5420-5425.

Salas, S., and Gaertner, D. 2004. The behavioural dynamics of fishers: management implications. Fish Fish. 5: 153-167.

Squires, D. 2010. Fisheries buybacks: a review and guidelines. Fish Fish. 11: 366-387.

Sumaila, U.R., Teh, L., Watson, R., Tyedmers, P., and Pauly, D. 2008. Fuel price increase, subsidies, overcapacity, and resource sustainability. ICES J. Mar. Sci. 65(6): 832-840.

Trenkel, V.M., and Rochet, M.-J. 2010. Combining time trends in multiple metrics for identifying persistent changes in population processes or environmental stressors. J. Appl. Ecol. 47: 751-758.

Trenkel, V.M., Rochet, M.-J., and Mesnil, B. 2007. From model-based prescriptive advice to indicator-based interactive advice. ICES J. Mar. Sci. 64(4): 768-774.

Trenkel, V.M., and Rochet, M.J. 2003. Performance of indicators derived from abundance estimates for detecting the impact of fishing on a fish community. Can. J. Fish. Aquat. Sci. 60: $67-85$.

Ulrich, C., Le Gallic, B., Dunn, M.R., and Gascuel, D. 2002. A multi-species multi-fleet bioeconomic simulation model for the English Channel artisanal fisheries. Fish. Res. 58: 379-401.

Van Iseghem, S., Quillérou, E., Brigaudeau, C., Macher, C., Guyader, O., and Daurès, F. 2011. Ensuring representative economic data: survey data-collection methods in France for implementing the Common Fisheries Policy. ICES J. Mar. Sci. 68: 1792-1799.

Vermard, Y., Marchal, P., Mahévas, S., and Thébaud, O. 2008. A dynamic model of the Bay of Biscay pelagic fleet simulating fishing trip choice : the response to the closure of the Anchovy fishery in 2005. Can. J. Fish. Aquat. Sci. 65: 2444-2453.

Whitmarsh, D., James, C., Pickering, H., and Neiland, A. 2000. The profitability of marine commercial fisheries: a review of economic information needs with particular reference to the UK. Mar. Policy 24: 257-263. 


\section{Tables}

Table 1. List of French fleets operating in the Bay of Biscay, main species caught by each fleet, mean annual dependence of this fleet on this species, and size of the principal species list: number of species that make up $75 \%$ of total annual catch of this fleet (the list was calculated annually and any species that occurred in at least one year was included in the final list). The number in the fleet code refers to main fishing grounds: 1 coastal fleets ( $<12$ n.mi. from coast), 2 mixed coastal and offshore fleets, 3 offshore fleets (beyond 12 n.mi.).

\begin{tabular}{|c|c|c|c|c|}
\hline Code & Fleet name & Main Species & Dependence & No species \\
\hline $1 \mathrm{NT}$ & Coastal NephropsTrawlers & Nephrops & 0.56 & 4 \\
\hline $1 \mathrm{~T}$ & Coastal Exclusive Trawlers & Sole & 0.14 & 15 \\
\hline $1 \mathrm{U}$ & Coastal Non Exclusive Trawlers & Sole & 0.18 & 29 \\
\hline $2 \mathrm{NT}$ & Coastal/Shelf Nephrops Trawlers & Nephrops & 0.54 & 5 \\
\hline 2BT & Coastal/Shelf Bottom Trawlers & Sole & 0.18 & 11 \\
\hline $2 \mathrm{MT}$ & Coastal/Shelf Mixed Bottom Pelagic Trawlers & Sardine & 0.14 & 18 \\
\hline $2 \mathrm{PT}$ & Coastal/Shelf Pelagic Trawlers & Anchovy & 0.22 & 10 \\
\hline $2 \mathrm{U}$ & Coastal/Shelf Non Exclusive Trawlers & Nephrops & 0.29 & 13 \\
\hline $3 \mathrm{NT}$ & Shelf Nephrops Trawlers & Nephrops & 0.47 & 7 \\
\hline 3BT & Shelf Bottom Trawlers & Monkfish & 0.33 & 16 \\
\hline $3 \mathrm{MT}$ & Shelf Mixed Bottom Pelagic Trawlers & Anchovy & 0.2 & 12 \\
\hline 3PT & Shelf Pelagic Trawlers & Anchovy & 0.47 & 5 \\
\hline $1 \mathrm{~S}$ & Coastal Seiners & Sardine & 0.48 & 7 \\
\hline $1 \mathrm{D}$ & Coastal Dredgers & Sea bass & 0.18 & 29 \\
\hline $1 \mathrm{~N}$ & Coastal Netters & Sea bass & 0.17 & 29 \\
\hline $1 \mathrm{NS}$ & Coastal Netters With Sole & Sole & 0.42 & 9 \\
\hline $1 \mathrm{Q}$ & Coastal Mixed Nets and Pots & Sole & 0.18 & 29 \\
\hline $1 \mathrm{E}$ & Coastal Mixed Nets and Hooks & Sea bass & 0.53 & 10 \\
\hline $1 \mathrm{ES}$ & Caostal Mixed Nets With Sole and Hooks & Sea bass & 0.35 & 10 \\
\hline $1 \mathrm{P}$ & Coastal Potters & $\mathrm{Crab}$ & 0.2 & 29 \\
\hline $1 \mathrm{~F}$ & Coastal Mixed Pots and Hooks & Sea bass & 0.34 & 29 \\
\hline $1 \mathrm{H}$ & Coastal Liners & Sea bass & 0.63 & 3 \\
\hline $2 \mathrm{NS}$ & Coastal/Shelf Netters With Sole & Sole & 0.64 & 5 \\
\hline $2 \mathrm{H}$ & Coastal/Shelf Liners & Conger eel & 0.5 & 4 \\
\hline $3 \mathrm{NS}$ & Shelf Netters With Sole & Hake & 0.33 & 6 \\
\hline $3 \mathrm{~N}$ & Shelf Netters & Hake & 0.65 & 3 \\
\hline $1 \mathrm{G}$ & Coastal Sievers & Sea bass & 0.26 & 29 \\
\hline
\end{tabular}


Table 2. Main fleet depending on each species, the mean annual contribution of this fleet to the catch this species, and the number of fleets that make up $75 \%$ of total annual catch of this species.

\begin{tabular}{|c|c|c|c|c|c|}
\hline $\begin{array}{l}\text { Species } \\
\text { code }\end{array}$ & Common name & Scientific name & Main fleet & Contribution & $\begin{array}{l}\text { No. of } \\
\text { fleets }\end{array}$ \\
\hline$\overline{\mathrm{ANC}}$ & Anchovy & Engraulis encrasicholus & Shelf pelagic trawlers & 0.44 & 4 \\
\hline BAS & Sea bass & Dicentrarchus labrax & Coastal liners & 0.14 & 17 \\
\hline MON & Monkfish & Lophius budegassa, Lophius piscatorius & Shelf bottom trawlers & 0.33 & 8 \\
\hline SQU & Squid & Loligo forbesi, Lologo vulgaris & Coastal-shelf bottom trawlers & 0.34 & 7 \\
\hline HOR & Horse mackerel & Trachurus trachurus & Coastal seiners & 0.38 & 9 \\
\hline $\mathrm{CON}$ & Conger eel & Conger conger & Coastal liners & 0.24 & 13 \\
\hline MHO & $\begin{array}{l}\text { Mediterranean } \\
\text { horse mackerel }\end{array}$ & Trachurus mediterraneus & Coastal seiners & 0.46 & 5 \\
\hline SCA & Scallop & Pecten maximus & Coastal non-exclusive trawlers & 0.57 & 2 \\
\hline ALB & Albacore & Thunnus alalunga & Shelf mixed bottom pelagic trawlers & 0.24 & 8 \\
\hline MAC & Mackerel & Scomber scombrus & Coastal seiners & 0.17 & 11 \\
\hline WHI & Whiting & Merlangus merlangius & Coastal-shelf bottom trawlers & 0.16 & 20 \\
\hline HAK & Hake & Merluccius merluccius & Shelf netters & 0.29 & 14 \\
\hline MUL & Mullets & Mugillidae & Coastal seiners & 0.19 & 13 \\
\hline CUC & Cuckoo ray & Leucoraja naevus & Shelf bottom trawlers & 0.61 & 4 \\
\hline RED & Red mullet & Mullus surmuletus & Coastal-shelf bottom trawlers & 0.17 & 13 \\
\hline CAT & Catshark & Scyliorhinus canicula & Coastal-shelf Nephrops trawlers & 0.19 & 10 \\
\hline SAR & Sardine & Sardina pilchardus & Coastal seiners & 0.75 & 3 \\
\hline CUT & Cuttlefish & $\begin{array}{l}\text { Sepia elegans, Sepia officinalis, } \\
\text { Sepia orbignyana }\end{array}$ & Coastal-shelf bottom trawlers & 0.21 & 12 \\
\hline SOL & Sole & Solea solea & Coastal-shelf netters with sole & 0.31 & 12 \\
\hline
\end{tabular}

Note: The list was calculated annually and any fleet that occurred in at least 1 year was included in the final list. 
Table 3. Expected changes from press perturbation analysis of changes in economic and ecological variables of the simple fleetstock model in Fig. 1.

\begin{tabular}{|c|c|c|c|c|}
\hline \multirow[b]{2}{*}{ Perturbation: change in driver } & \multicolumn{4}{|c|}{ Impact on } \\
\hline & $S$ & $K$ & $R$ & $P$ \\
\hline Increased $B$ & $(+)$ & + & + & + \\
\hline Vessel buyback & + & - & $?$ & $(+)$ \\
\hline Increased $G$ & + & - & - & - \\
\hline Increased $P$ & - & + & + & + \\
\hline Vessel buyback and increased $G$ & + & - & $?$ & $?$ \\
\hline $\begin{array}{l}\text { Increased } B \text {, increased } G \text {, and } \\
\text { increased } P\end{array}$ & $(+)$ & $(+)$ & $(+)$ & $(+)$ \\
\hline $\begin{array}{l}\text { Vessel buyback, increased } G \text {, and } \\
\text { increased } P\end{array}$ & $?$ & $?$ & $?$ & $?$ \\
\hline $\begin{array}{l}\text { Vessel buyback, increased } G \text {, and } \\
\text { increased } B\end{array}$ & $(+)$ & $?$ & $?$ & $?$ \\
\hline $\begin{array}{l}\text { Vessel buyback, increased } G \text {, } \\
\text { increased } B \text {, and increased } P\end{array}$ & $?$ & $?$ & $?$ & $?$ \\
\hline
\end{tabular}

Note: + , increase; - , decrease; results in parentheses are ambiguous (not all but a majority of loops in the same direction); ?, very ambiguous (almost as many loops in each direction; thus, the overall effect will depend on interaction strength); $S$, stock; $K$, capacity; $R$, net earnings; $P$, profitability; $B$, environmental productivity; $G$, fuel price; $P$, ex-vessel fish price. Expected effects on wages are the same as on net earnings. 
Table 4. Consistency between trends in drivers (fleet capacity) and impacts on stock status (number of stocks with each trend combination).

\begin{tabular}{lccc}
\hline & \multicolumn{2}{l}{ Fishing impact on stock } \\
\cline { 2 - 4 } Fleet capacity & Non-increasing & No change & Non-decreasing \\
\hline Time lag = 1 year & 3 & 16 & 1 \\
Decrease & 1 & 1 & 1 \\
No change & 0 & 2 & 0 \\
Increase & & &
\end{tabular}

Without time lag

Decrease

No change

Increase

\begin{tabular}{|c|c|c|}
\hline 10 & 9 & 1 \\
\hline 1 & 2 & 0 \\
\hline 1 & 1 & 0 \\
\hline
\end{tabular}

Note: Shaded cells are those with consistent trends according to predictions for the simple fleet-stock model in Fig. 1 (some of which are provided in Table 3), assuming the only driver would be changes in fleet capacity. Results are shown for the 25 biological species for which survey data are available (see list in Fig. 8). 
Table 5. Summary of consistency between trends in drivers (stock status and fish price) and impacts on fleet dynamics (trends in fishing capacity; number of fleets with each trend combination).

\begin{tabular}{|c|c|c|c|c|c|c|}
\hline \multirow[b]{3}{*}{ Fleet capacity } & \multicolumn{3}{|c|}{ Stock change uncertain } & \multicolumn{3}{|c|}{ Stock change nondetrimental } \\
\hline & \multicolumn{3}{|l|}{ Fish price } & \multicolumn{3}{|l|}{ Fish price } \\
\hline & Decrease & No change & Increase & Decrease & No change & Increase \\
\hline \multicolumn{7}{|c|}{ Time lag $=1$ year } \\
\hline Decrease & 0 & 0 & 1 & 1 & 1 & 8 \\
\hline No change & 0 & 0 & 0 & 0 & 1 & 11 \\
\hline Increase & 0 & 0 & 0 & 0 & 0 & 4 \\
\hline
\end{tabular}

Without time lag

Decrease

No change

Increase

\begin{tabular}{llllll}
1 & 0 & 0 & 4 & 3 & 3 \\
1 & 0 & 0 & 6 & 0 & 5 \\
0 & 0 & 0 & 3 & 0 & 1 \\
\hline
\end{tabular}

Note: Shaded cells are those with consistent trends according to predictions for the simple fleet-stock model in Fig. 1 (some of which are provided in Table 3), assuming that fleet capacity is driven by external drivers: increasing fuel price, trends in fish price, and stock status. "No change" means no trend or ambiguous combination. 
Figures

Figure 1. Simple fleet-stock model on an annual time scale. S stock, K fishing capacity, E effort, $\mathrm{C}$ catch, $\mathrm{R}$ net earnings, P Profitability, $\mathrm{W}$ wages. Arrow-ended links indicate positive effects, bullet-ended links indicate negative effects; all variables are self-regulated, thus the negative self-effects. External drivers that do not act as active variables within the system but create perturbations are shown in grey with dashed lines.

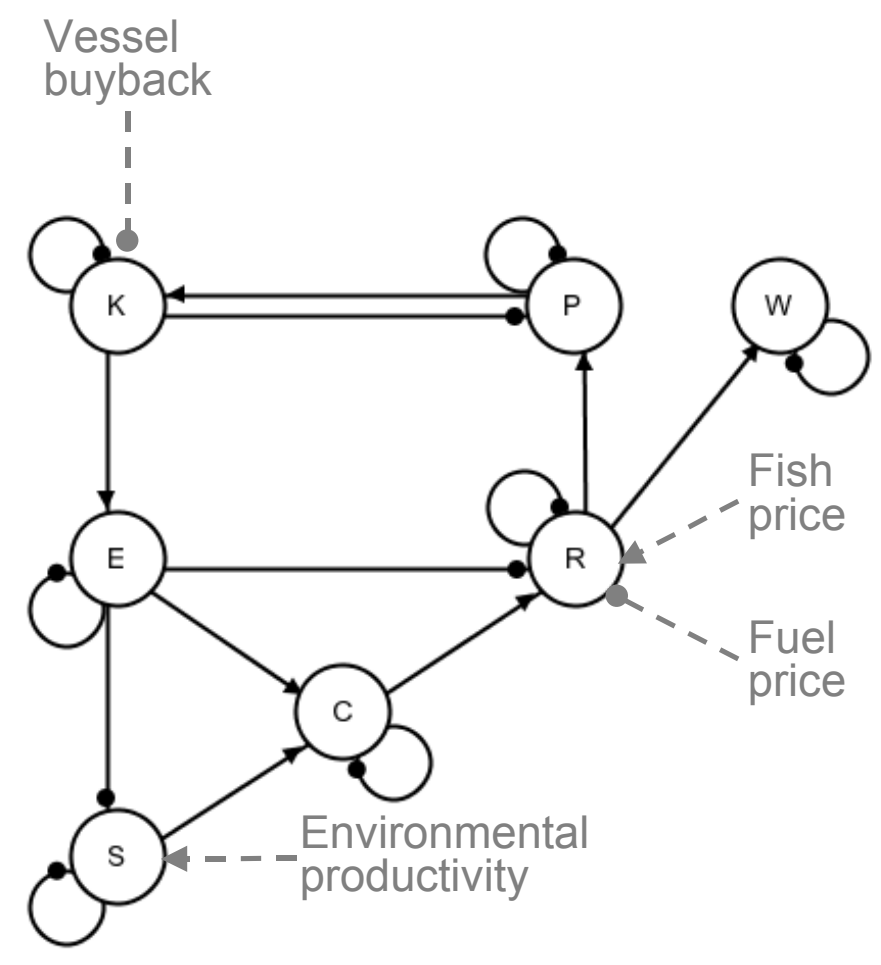


Figure 2. The Bay of Biscay. Continuous lines are limits of survey strata - either depth contours $(30,80,120,160,200$ and $400 \mathrm{~m})$ or limits between Northern and Southern areas.

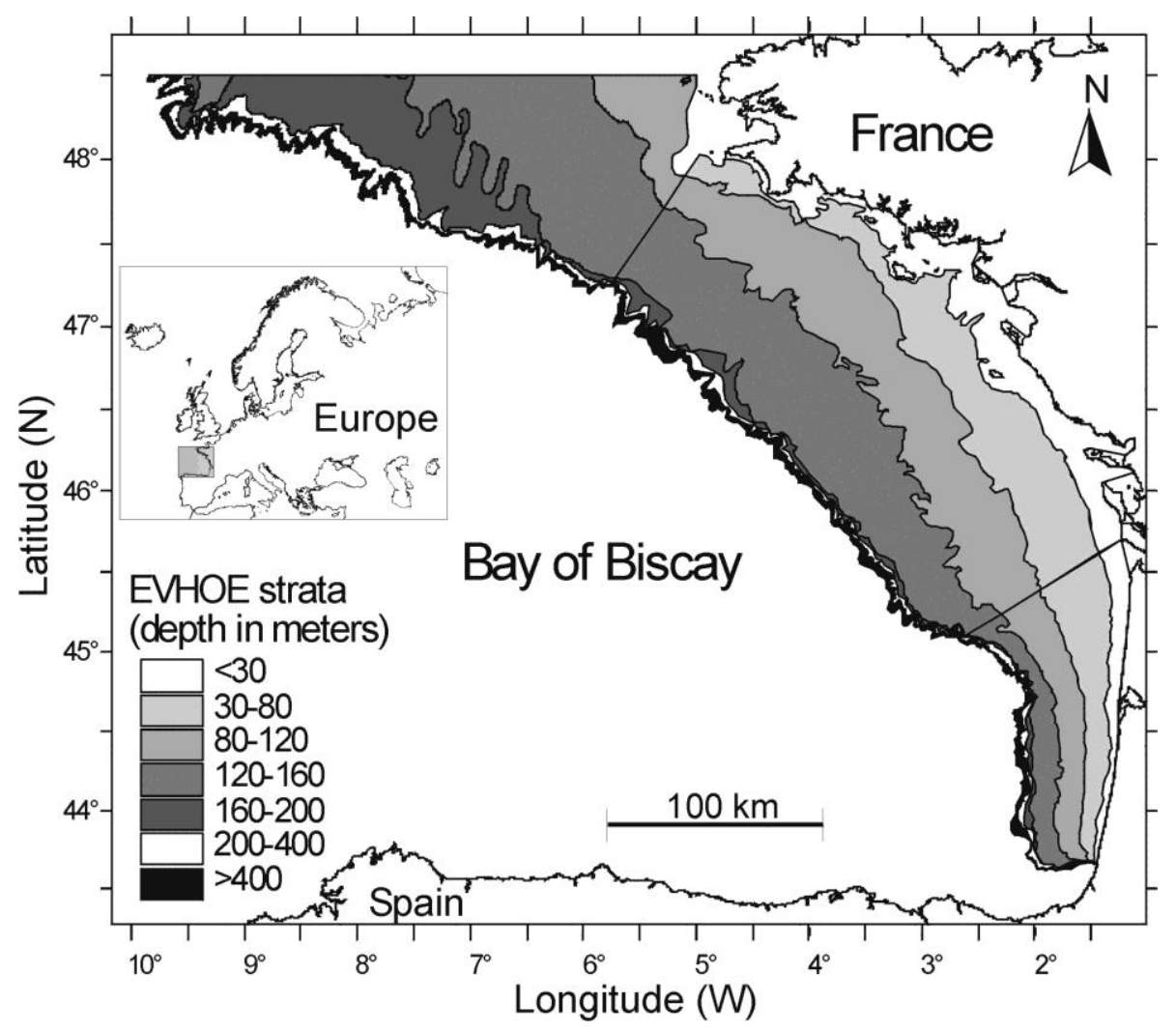


Figure 3. Trends in (a-c) capacity and (d-f) economic metrics of three fleets: $a, d)$ coastal non exclusive trawlers (d: profitability), b, e) coastal/shelf bottom trawlers (e: wages), and c, f) coastal seiners (f: net earnings). Circles show normalized data points (with error bar: assumed $1 \%$ CV for capacity, sampling error for economic metrics), lines fitted GAM model constrained to increase or decrease, or the "no change" model. Line width proportional to likelihood of fit.

(a)

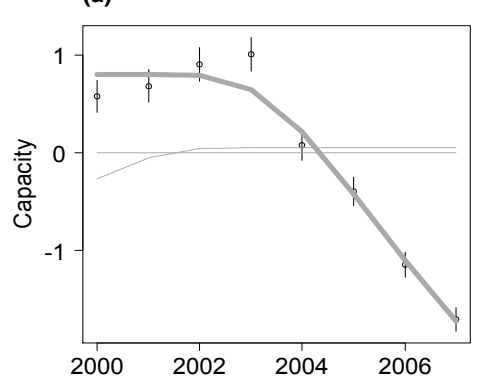

(d)

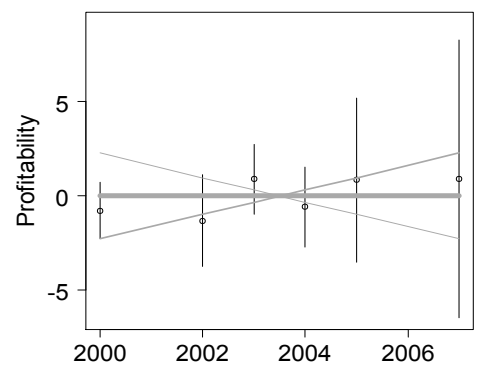

(b)

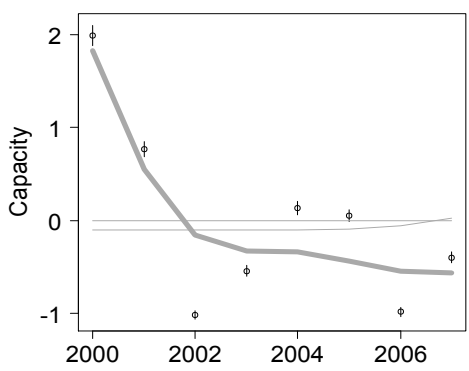

(e)

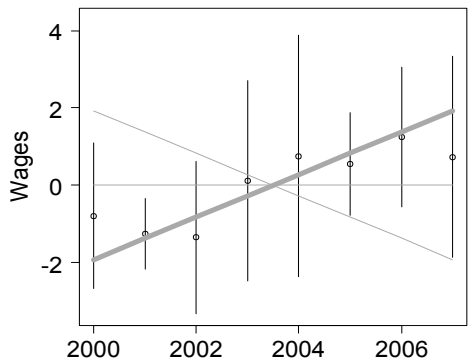

(c)

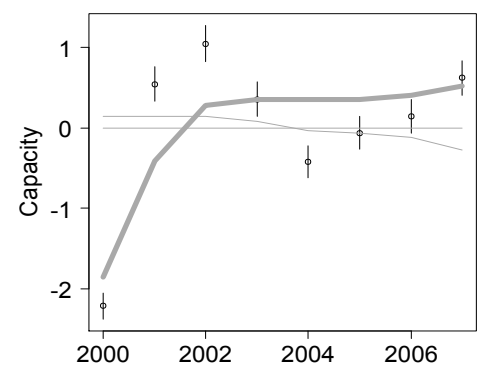

(f)

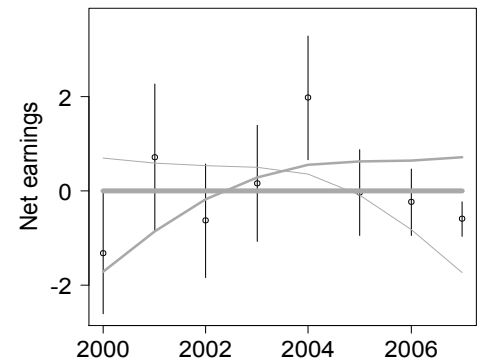


Figure 4. Species metrics: abundance (left), $\mathrm{L}_{0.75}$ (middle), and price (right). Circles show annual estimates with $95 \%$ confidence intervals. Monkfish is Lophius piscatorius.

(a)

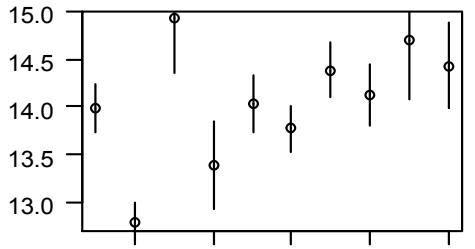

(d)

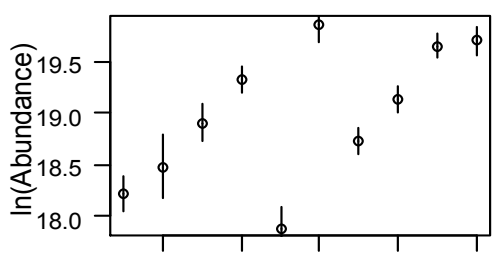

(g)

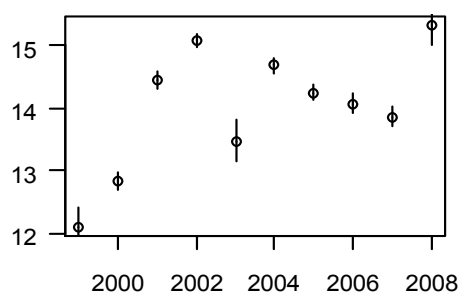

(b)

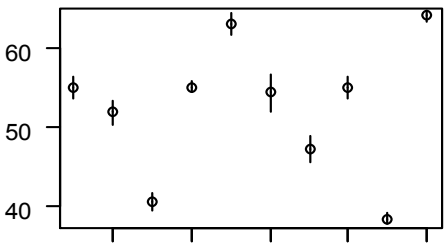

(e)

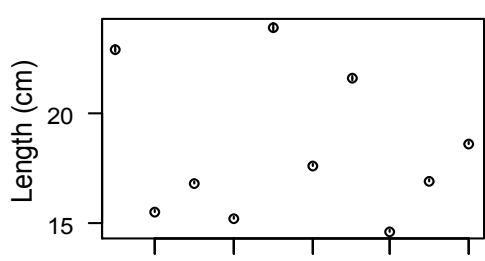

(h)

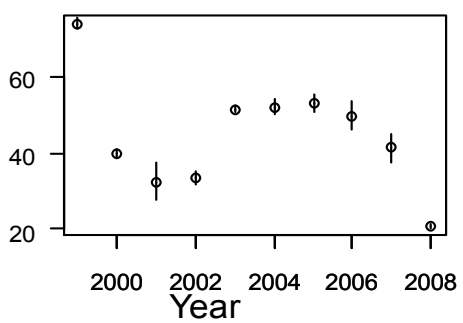

(c)

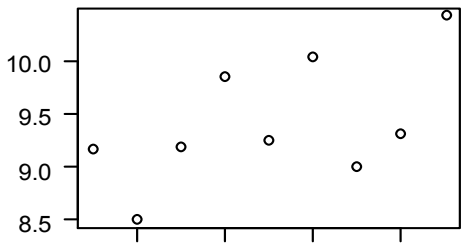

(f)

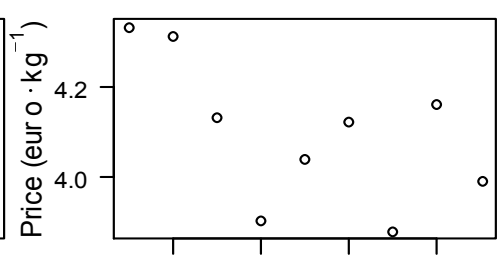

(i)

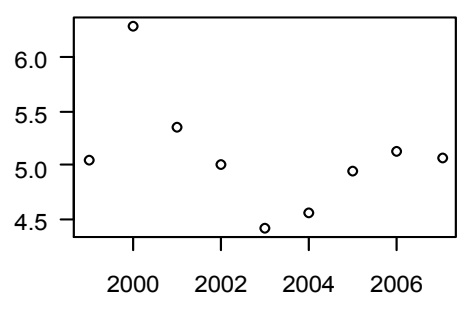

Figure 5. Trends in price of fuel in France 2000-2009 (http://www.developpementdurable.gouv.fr/energie/petrole/se_cons_fr.htm). Lines show fitted GAM models constrained to increase or decrease, or the "no change" model; line width proportional to likelihood of fit.

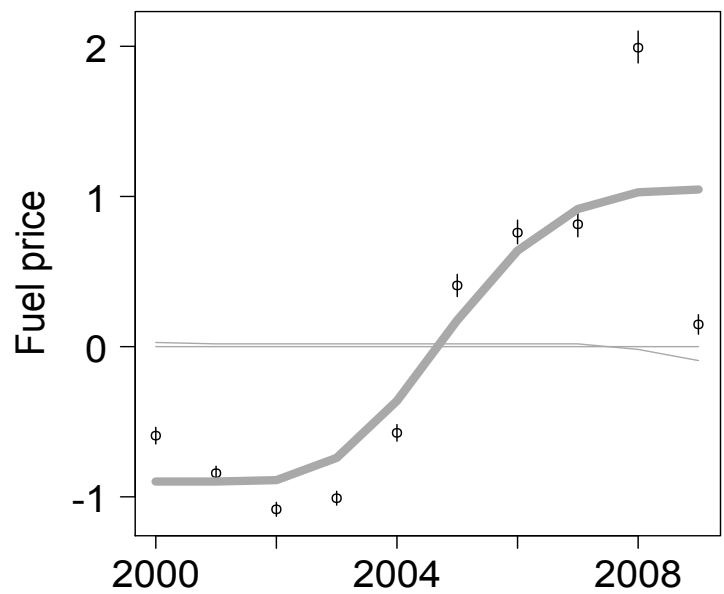


Figure 6. Fleet contribution profiles in 2006 for three stocks, sardine (a), anchovy (b) and sea bass (c). Bars show cumulated contribution of each fleet to total landings (in weight) for a respective stock; fleets ranked by decreasing contribution (see fleet codes in Table 1). Dashed line shows the $75 \%$ threshold determining the list of fleets included in the calculations as exerting a pressure on the stock.
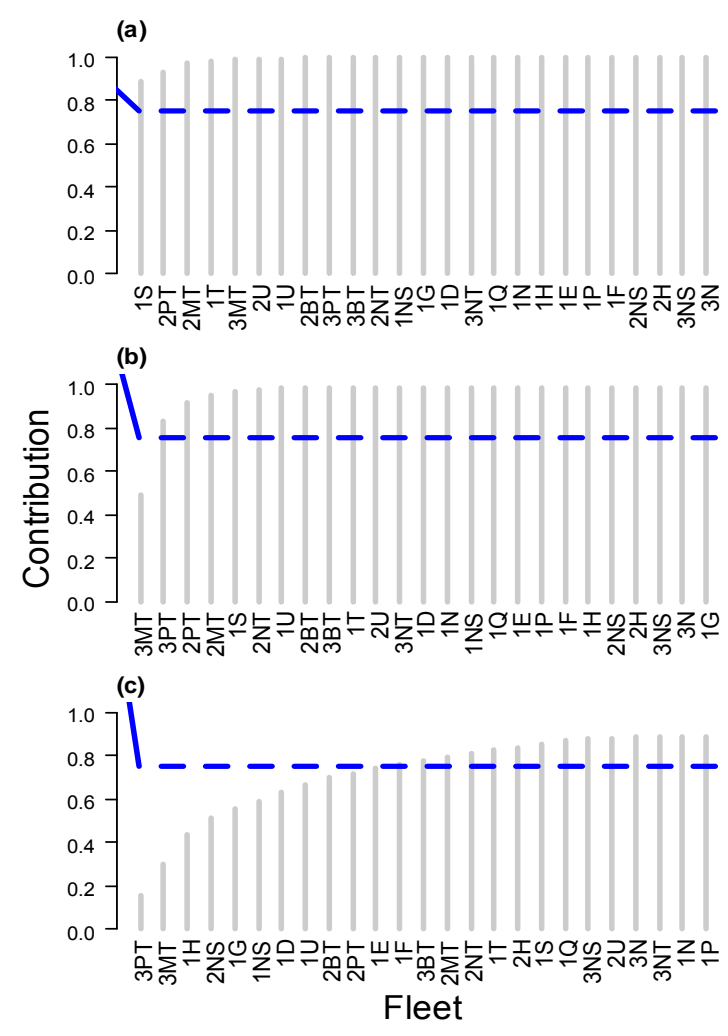
Figure 7. Stock dependence profiles in 2006 for three fleets, coastal exclusive trawlers (a), shelf mixed bottom pelagic trawlers (b), and shelf pelagic trawlers (c). Bars show cumulated dependence (in value) on each stock of a respective fleet; stocks ranked by decreasing dependence. Dashed line shows the $75 \%$ threshold determining the list of stocks of which a fleet depends, thus included in the calculations as having an effect on the fleet.

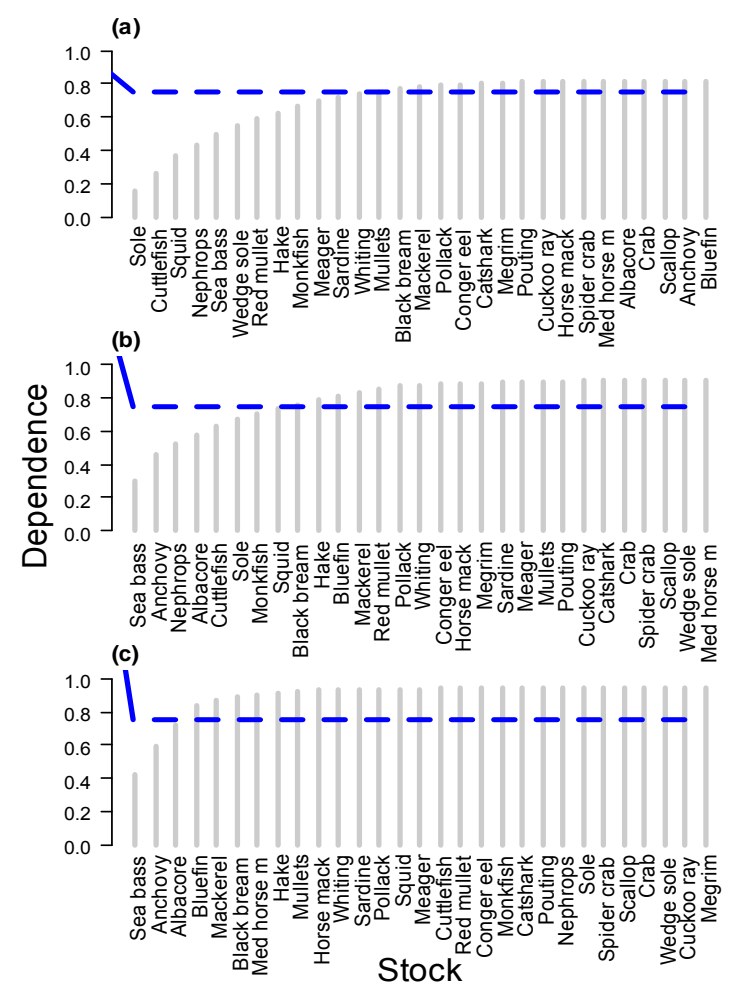


Figure 8. Trends in the fishing capacity of the major fleets catching each stock 2000-2007, and diagnostics of changes in fishing impact on fish stocks 2001-2008. Black: most likely process, dark grey: less likely process, light grey: no change most likely, white: no data. Stocks are ordered by trend in the capacity of the fleets exploiting them. Squid (f) Loligo forbesi, (v) $L$. vulgaris; Cuttlefish (ele) Sepia elegans, (off) S. officinalis, (orb) S. orbibgnyana.
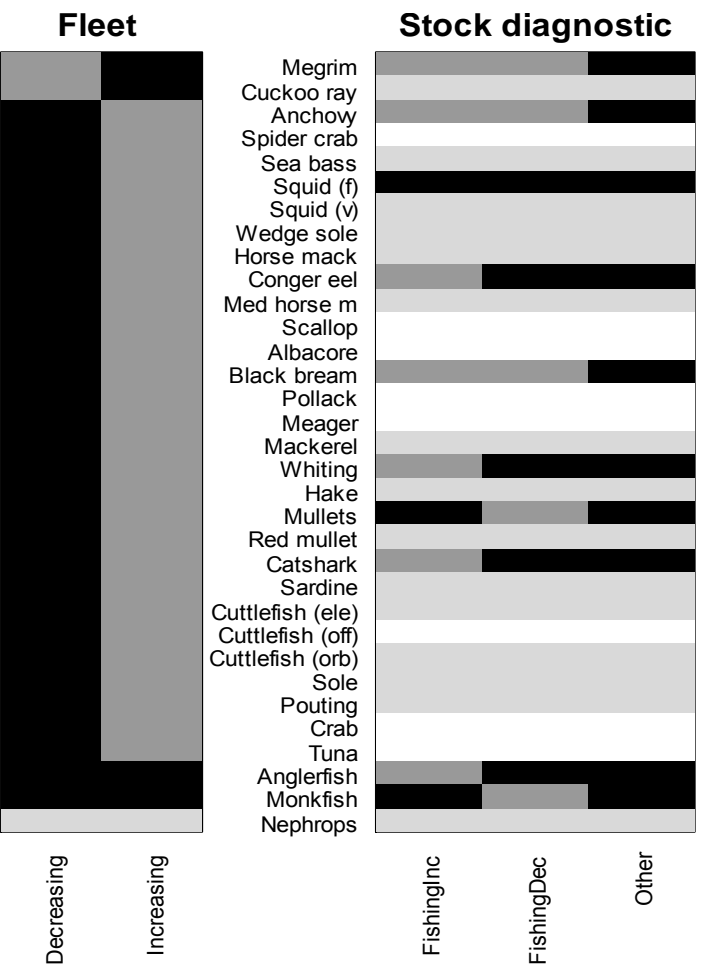
Figure 9. Trends in drivers of fleet dynamics 1999-2006, and in fleet capacity, 2000-2007. Price: combined trends in the price of the major stocks. Resource: combined trends in the status of the major stocks (stars indicate fleets for which data are available for less than $75 \%$ of stocks in the mix). Black: most likely process, dark grey: less likely process, light grey: no change most likely, white: no data. Fleets are ordered by combined trends in price.

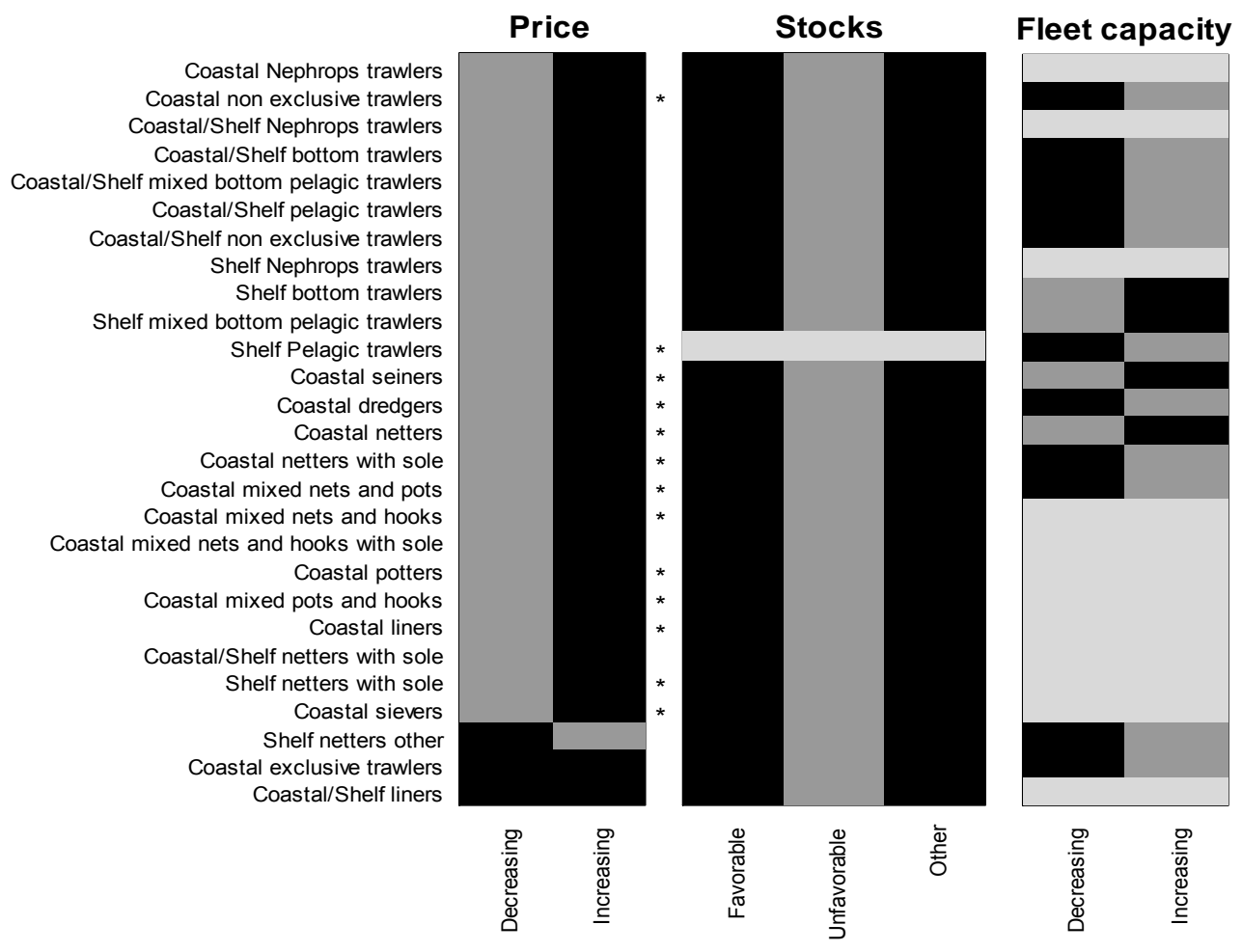

Figure 10. Trends in fleet metrics 2000-2007 for the 12 fleets with economic data. Black: most likely process, dark grey: less likely process, light grey: no change most likely, white: no data. Fleets are ordered by trend in net earnings.

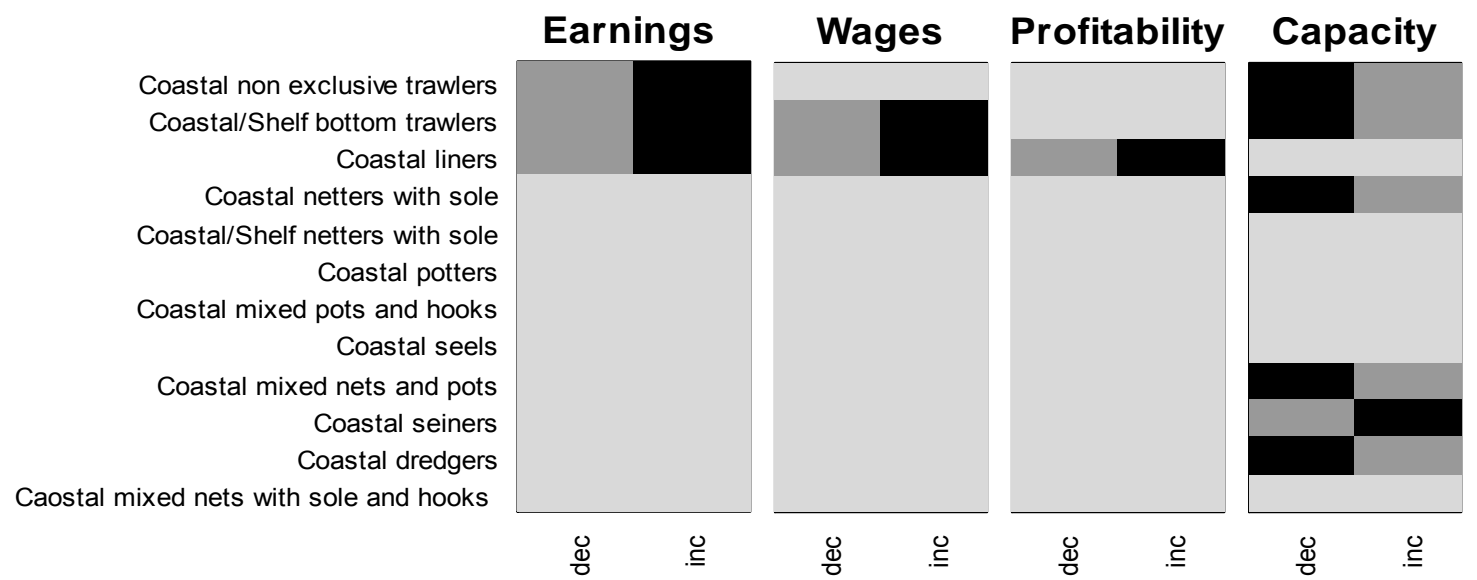

